\title{
On the Application of the Installation UOV-7757 "Arasan" for the Production of Biologically Active Water and Conducting the Infra-Acoustic Vibration Wave Massage Procedures
}

\author{
Namazbaeva ZI* \\ Doctor of Medical Sciences, Professor, Russia \\ *Corresponding author: Namazbaeva ZI, Doctor of Medical Sciences, Professor, Russia
}

\begin{tabular}{|c|c|}
\hline ARTICLE INFO & ABSTRACT \\
\hline Received: 豐 March 29, 2019 & Citation: Namazbaeva ZI. On the Application of the Installation UOV-7757 "Arasan" for the \\
\hline Published: 慧 April 08, 2019 & $\begin{array}{l}\text { Production of Biologically Active Water and Conducting the Infra-Acoustic Vibration Wave } \\
\text { Massage Procedures. Biomed J Sci \& Tech Res 16(5)-2019. BJSTR. MS.ID.002920. }\end{array}$ \\
\hline
\end{tabular}

\section{Opinion}

Modern medicine in its development is on the way to improve pharmaceuticals with the aim of selective, targeted effects on organs and cells. All her efforts to cure are directed not at the cause of the disease, but at combating its consequences. In this regard, the urgency of identifying the causes of the disease and the influence of the side effects of drug therapy on human health is increasing worldwide. According to epidemiological studies, the side effects of drug therapy in the United States and Canada are ranked 5-6 in explaining the causes of death after cardiovascular, oncological, bronchopulmonary diseases and injuries. Every year in the US, more than 106.0 thousand patients die from side effects of drugs. In this case, we are talking about cases when the doctor correctly diagnosed, prescribed medications correctly, and the patient took them correctly. According to leading scientists, the existing technologies of the "health industry" are depleting their potential and new developments are needed on fundamentally new approaches to ensuring people's health.

It is known that the human body is $70 \%$ water. Studies have shown the difference in the physical parameters of the aquatic environment in a healthy organ and in the same organ, but in the patient. It should be noted that getting into our body, ordinary water undergoes a number of biophysical changes and only then acquires the properties necessary for our internal aquatic environment, while spending a significant amount of energy. Under ideal conditions, the body has enough funds to convert drinking water into the necessary aquatic environment and maintain the necessary parameters of the internal fluid. But in real life, a number of serious external factors - such as nutrition, lifestyle, the environment, viruses, bacteria, etc. have a great influence on this process. And often it turns out that the body spends energy on interacting with these external factors. As a result, over time, he begins to lack internal resources to maintain the necessary parameters of the internal environment. From this point on, a person has serious health problems. They usually begin with a weakening of the immune system, hypoxia of the brain and heart muscle, metabolic disorders occurring against the background of chronic fatigue syndrome. One of the promising innovative directions for solving the above problems is the use of the method of infra-acoustic vibro-wave massage procedure of a sick organ developed in our country with the subsequent intake of biologically active water necessary for the proper functioning of all organs and body systems. The developed technology of obtaining biologically active water with given physical parameters ensures the coincidence of the $\mathrm{pH}$ of the produced water with the $\mathrm{pH}$ of the blood of a healthy person. Ingestion of such water provides minimal energy costs for obtaining the optimal range of $\mathrm{pH}$ values of blood $\mathrm{pH}$, which is necessary for the vital functions of the body.

Only such blood is able to fully supply the body with nutrients and remove waste of cell activity. It should be noted that the technology of obtaining biologically active water is based on the use of ordinary natural water without the introduction of any activators and stabilizers. The installation of water treatment and 
massage device UOV-7757 "Arasan" was developed on the basis of the international Eurasian patent for the invention: Namazbaev TS, Namazbaeva ZI "Installation of water treatment by external physical impact." Patent for the invention of the Eurasian Patent Office No. 025259, Moscow, M. Cherkassky Lane. 2. Date of publication and issuance of the patent for the invention is December 30, 2016. RSE "Committee for Technical Regulation and Metrology" of the Ministry of Investment and Development of the Republic of Kazakhstan issued a certificate No. 14396 of August 21, 2017, certifying that, based on positive test results, the type was approved: "Installation of water treatment by external physical impact UOV-7757" Arasan " produced by JSC Kazchermetavtomatika and approved for production in the Republic of Kazakhstan. The certificate on the origin of the goods according to the ST-KZ form No. KZ 7 dated 03.03.2017 was obtained.

Regular use of biologically active Arasan water with an optimal $\mathrm{pH}$ value and conducting infraacoustic vibration wave massage procedures has a complex positive effect on many human functional systems: - has an immunostimulating effect; positively affects the functioning of the brain, gastrointestinal tract, endocrine and cardiovascular systems, thyroid, liver, kidneys, etc . restores violations of exchange processes, eliminating their causes; - decreases blood viscosity, improves capillary blood supply, normalizes blood pressure. The scientific novelty of the proposed infraacoustic vibration wave massage procedure based on the use of the Arasan UOV-7757 installation with the determination of the entropy coefficient by the method of bioresonant testing is confirmed by the patent of the Republic of Kazakhstan for the invention: Namazbayev TS, Namazbayeva ZI "Diagnostic and therapeutic complex". Patent of the Republic of Kazakhstan for invention № 28386, publ. in bul. № 6 dated 15.06.2016. In the block of bioresonant testing of the installation UOV-7757 "Arasan" before the start of the massage procedures, an expert assessment of the patient's condition is carried out with the determination of the entropy coefficient reflecting the state of the massaged organ. Based on the operational information of bioresonance testing on the condition of the patient's massaged organ, the parameters of the infra-acoustic vibrowave effect on the massaged organ are determined.It was found that the infra-acoustic vibration wave effect on the mammary gland of variable frequency with a predetermined

\section{ISSN: 2574-1241}

DOI: 10.26717/BJSTR.2019.16.002920

Namazbaeva ZI. Biomed J Sci \& Tech Res

This work is licensed under Creative Commons Attribution 4.0 License

Submission Link: https://biomedres.us/submit-manuscript.php algorithm for changing it with the help of the installation UOV-7757 has a healing effect in mastitis.

The scientific novelty of the developed innovative technology of rehabilitation in mastopathy is confirmed by the international Eurasian patent for the invention: Z. Namazbaeva, T. Namazaev. and others. "The method of treatment of mastopathy." Patent for the invention of the Eurasian Patent Office No. 030520, Moscow, M. Cherkassky Lane. 2. Date of publication and issuance of a patent for an invention is August 31, 2018. In our country, the diagnosis of iodine deficiency and microelementosis in the body and its prevention is carried out in accordance with the Law of the Republic of Kazakhstan No. 489-11 on the prevention of iodine deficiency diseases of October 14, 2003. It has been established that the combined use of an aqueous solution of biologically active iodine and an infra-acoustic vibro-wave massage procedure with the aid of the installation УOB-7757 "Arasan" increases the efficiency of the patient's recovery from diseases of the thyroid gland and allows normalizing the level of their hormones without using hormone replacement therapy. The scientific novelty of the proposed method is confirmed by the patent of the Republic of Kazakhstan for the invention: Z. Namazbaeva, TS Namazbaev, K.A. Alikhanov. "A method for the treatment of diseases of the thyroid gland." Patent of the Republic of Kazakhstan for invention № 28427, publ. in bul.

№5 from 05.15.2014. Biologically active water "Arasan" in its parameters corresponds to the special physical state of the intercellular fluid of our body and is not a drug. If the physical parameters of the body's fluid medium are chosen correctly, then the biochemical reactions in the cells proceed as expected. Therefore, in many cases, the regular use of biologically active Arasan water with the conduct of infra-acoustic vibration-wave massage procedures works better than any medicinal preparations, triggering the processes of self-healing and self-healing of the body. Regular use of biologically active water "Arasan" with the conduct of infraacoustic vibration-wave massage procedures creates conditions in which our body itself, if there are sufficient internal resources, is able to recover and cope with many of the ailments inherent in modern man within quite a reasonable time. With the regular use of biologically active water "Arasan", a person's biological age is reduced by 6-10 years. While receiving Arasan biologically active water, stresses disappear, sleep is restored.

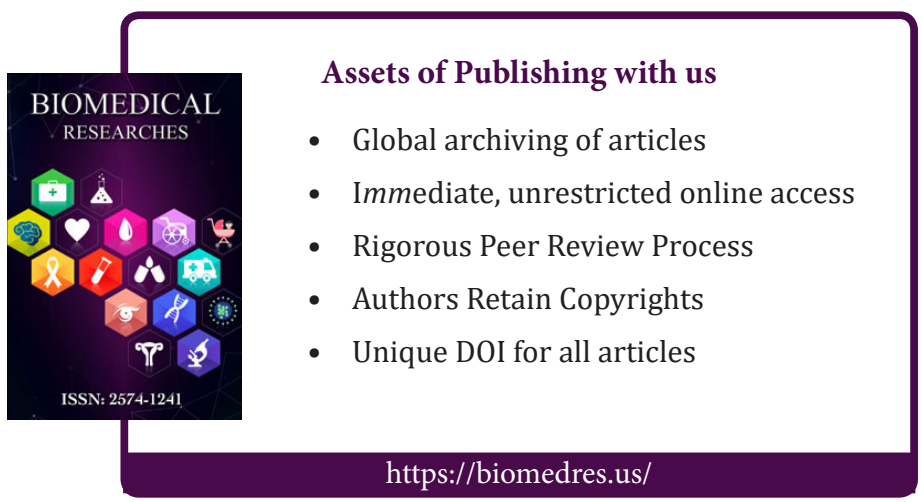

Copyright@ Namazbaeva ZI | Biomed J Sci \& Tech Res| BJSTR. MS.ID.002920. 